\title{
A CENTRALIDADE URBANA DE SETE LAGOAS NAREGIÃO CENTRAL DE MINAS GERAIS: O QUE REVELAMOS FLUXOS POPULACIONAIS
}

\author{
Marly Nogueira \\ Ricardo Alexandrino Garcia"
}

\section{Resumo}

O crescimento urbano deve ser considerado como um dos fenômenos mais importantes da realidade socioeconômica e espacial mineira. Os fluxos populacionais - emigração. imigração e movimentos pendulares - constituem, por sua vez, tema de real interesse, por causa de seu alto poder explicativo acerca das interações e das articulações que os lugares (cidades) estabelecem entre si. Tomando como exemplo Sete Lagoas (MG) é que se pretende neste trabalho elaborar uma espacialização dos fluxos populacionais, de e para tal municipalidade, nos últimos decênios, para tornar inteligível, pelo menos em parte, a sua centralidade na rede urbana mineira.

Palavras - Chave: centralidade urbana, rede urbana mineira, Fluxos populacionais, Sete Lagoas

'Dr ${ }^{a}$. Prof ${ }^{a}$. Departamento de Geografia/UFMG

'Dr. Prof. Departamento de Geografia/UFMG 


\section{1- INTRODUÇÃO}

O crescimento demográfico, sobretudo em sua dimensão urbana, deve serconsiderado como um dos fenômenos mais importantes da realidade socioeconômica e espacial de Minas Gerais. A temática dos fluxos populacionais - emigração. imigração e movimentos pendulares -, constitui, por sua vez, tema de real interesse, sobretudo, por causa de seu alto grau de teor explicativo acerca das interações e das articulações que os lugares (cidades) estabelecem entre si. Assim, tomando como exemplo empírico a cidade de Sete Lagoas, (MG) é que se pretende neste trabalho elaborar uma espacialização dos fluxos migratórios, além dos movimentos pendulares, de e para tal cidade, em busca de tornar inteligível, pelo menos em parte, sua centralidade na rede urbana mineira, nos últimos decênios.

Segundo Nogueira (2003) a cidade de Sete Lagoas tem se destacado nos últimosdecênios pelo expressivo florescimento econômico e demográfico que se reflete, por seu turno, numa importância cada vez maior da mesma diante do ambiente geral da globalização e na sua própria funcionalidade na rede urbana. De fato, toda essa configuração torna Sete Lagoas uma verdadeira cidade média, cuja centralidade na rede urbana mineira, já foi investigada e descrita pela autora acima referida (NOGUEIRA, 2003). Todavia, é importante verificar a contribuição dos estudos sobre os fluxos migratórios na complementação dessa investigação e descrição, ou seja, até que ponto os fluxos populacionais - migratórios e pendulares -, conseguem expressar a centralidade de Sete lagoas, uma típica cidade média, localizada na região central de Minas Gerais?Que tipo de centralidade os fluxos populacionais proporcionariam? Essa dimensão da centralidade urbana se esgotaria em si mesma? Tendo em vista os questionamentos apontados é que se vai, a seguir, discutir algumas proposições acerca da centralidade urbana sete-lagoana, complementada pela análise dos três tipos de fluxos populacionais em três períodos diferentes.

\section{A centralidade urbana de Sete Lagoas}

A cidade de Sete Lagoas quase sempre ocupou uma posição de expressiva centralidade na região na qual se localiza. Azevedo (1963) já havia salientado esse fato, quando descreve a região na qual surgiu Sete Lagoas, destacando que a cidade, desde há muito tempo, é o centro de uma região cuja paisagem é bastante peculiar. A característica fisionômica regional, dada pela predominância dos calcários, influenciou de maneira definitiva o povoamento e a organização do habitat regional, destacou a referida autora. 
A localização de Sete Lagoas, nas proximidades de Belo Horizonte, distando cerca de $70 \mathrm{Km}$ em direção noroeste, com efeito, lhe confere uma posição privilegiada, pois está no contato de duas grandes regiões fisionômicas e socioespaciais no conjunto do Estado de Minas Gerais. Está-se falando do contato entre o Quadrilátero Ferrífero, zona de ocorrência predominante de minerais ferrosos e da floresta tropical úmida, comovegetação primitiva do centro-sul e leste (as Minas) e a região dos calcários do Bambuí, com uma típica vegetação de cerrado na qual sobressaem os campos limpos e os cocais, os quais, por sua vez, encontram-se conjugados a uma presença marcante das pastagens (as Gerais).

Enquanto as regiões do Espinhaço e do Quadrilátero Ferrífero iriam assistir ao desenvolvimento das atividades mineradoras do ouro, especialmente, mas também, do diamante e de muitas pedras preciosas e semipreciosas, aliado ao início da industrialização do ferro, com a instalação das primeiras forjas, ainda nos séculos XVII e XVIII, a região do São Francisco foi palco do florescimento das atividades pecuaristas. Tem-se, portanto, muito em função dessa compartimentação, a construção de duas grandes regiões muito diferentes entre si e que guardam as suas respectivas particularidades não só do ponto de vista da fisionomia mas, fundamentalmente, da economia, da socioespacialidade, enfim, da própria civilização que nelas floresceu. E foi no contato dessas duas regiões que Sete Lagoas surgiu. (consulte-se: ANASTÁSIA, 1983, AZEVEDO, 1963, CRUZ, 1984, LIMA JÚNIOR, 1965, MATA-MACHADO, 1986, PAULA, 1999, VASCONCELOS, 1974, VASCONCELOS, 1994 e VASCONCELOS, 1999)

Essa posição geográfica da cidade de Sete Lagoas influenciou profundamente não só seu destino, como também a organização espacial de sua região. De fato, em seus primórdios essa posição de contato foi a responsável pela sua função de boca-de-sertão, função essa, responsável em grande medida pelo destaque que a cidade adquiriu ao longo de sua história. E,muito embora já não seja mais possível debitar somente ou exclusivamente a essa posição geográfica a centralidade que Sete Lagoas continua mantendo na atualidade, é importante destacá-la, pois foi a partir da conjugação de fatores naturais e fatores socioespaciais que a cidade foi sendo forjada, construindo a sua própria singularidade, influenciando a organização espacial regional mais imediata para, finalmente, alcançar a atual inserção na rede urbana mineira.

A região central de Minas Gerais foi palco dos mais vitais episódios do ciclo da mineração do princípio do século XVII e durante o século XVIII, vendo aí surgir as primeiras vilas e cidades do Estado, ainda na primeira metade do século XVIII, dentre as quais deve-se citar: Mariana, a primeira delas, Ouro Preto, Sabará, São João del Rei, Caeté, Serro, Pitangui e Tiradentes. Com essa destacada quantidade de vilas, tornou-se consequência natural que se concentrasse ali um grande volume 
populacional, fato que afinal verificou-se, quando o primeiro recenseamento colonial, realizado em 1751, acusou uma população de 266.666 habitantes. (MINAS GERAIS, 1987).

Geiger e Corrêa (1971) apontam que na região central de Minas Gerais até, pelo menos, o princípio dos anos de 1970, a ausência de cidades de porte intermediário foi uma característica marcante. A região se apresentava com uma miríade de pequenas cidades sem expressão, centros locais mas, algumas delas com alguma indústria (a exceção ficava por conta da grande concentração urbana da Região Metropolitana de Belo Horizonte). A regionalização tornou-se impossibilitada, na medida em que não havia relações de complementaridade entre tais centros. No entanto, recorrendo a Bernardes (1964), é possível encontrar alguns fatos indicadores da relativa importância que algumascidades da região central mineira já possuíam na organização urbana da grande região do Rio de Janeiro. Desse modo, é que Sete Lagoas e Divinópolis aparecem na classificação elaborada como centros regionais de terceira categoria subordinados diretamente a Belo Horizonte. Essas duas cidades, em virtude de um acelerado processo de expansão econômica, já exerciam nessa época (anos de 1960) uma centralidade razoável em suas respectivas zonas de atuação. Mas, a tutela exercida por Belo Horizonte impediu que elas se tornassem verdadeiras capitais regionais. (BERNARDES, 1964).

A importância que Sete Lagoas e Divinópolis adquiriram ainda na década de 1960 pode ser, em grande medida, debitada às suas respectivas posições face à malha rodoferroviária. Com efeito, enquanto Divinópolis se firmou como entroncamento ferroviário, fato que favoreceu seu desenvolvimento industrial, tornando-a o foco da vida regional da porção sudoeste da região de Belo Horizonte e com projeção em direção ao oeste do estado, Sete Lagoas apresentava-se também com uma grande área de atuação, notavelmente favorecida pela abertura da rodovia que passou a ligar Belo Horizonte aBrasília (atual BR-040). Nessa época, a atuação sete-lagoana já se fazia presente em direção oeste e noroeste de Minas e a abertura da rodovia registrou um aprofundamento das relações da cidade com aquelas tradicionais áreas.

No estudo realizado pelo IBGE (1987) sobre as regiões de influência das cidades, uma adaptação da teoria das localidades centrais à realidade brasileira e que pretendeu ser uma revisão de um pioneiro estudo (IBGE,1972) sobre a divisão do Brasil em regiões funcionais urbanas, a cidade de Sete Lagoas figura como um centro sub-regional que, diretamente subordinado à metrópole regional de Belo Horizonte, parece confirmar as conclusões elaboradas por Bernardes (1964). Sob a tutela direta de Sete Lagoas estavam onze cidades: Araçaí, Baldim, Cachoeira dos Macacos (atual Cachoeira da Prata), Caetanópolis, Cordisburgo, Fortuna de Minas, Funilândia, Inhaúma, Jequitibá, Paraopeba e Santana de Pirapama e dois centros de zona Pedro Leopoldo e Pompéu. As cidades de Capim Branco, Matozinhos e Prudente de Morais subordinavam-se a Pedro Leopoldo e as cidades de Martinho Campos e Papagaios estavam sob a tutela direta de Pompéu. Importa frisar que a região de influência direta de 
Sete Lagoas muito pouco mudou nas duas ou três últimas décadas. Com exceção de Pompéu e de Pedro Leopoldo, esta segunda sendo atraída para a órbita direta da metrópole de Belo Horizonte, independizando-se ambas de Sete Lagoas, em verdade, a região que tal cidade subordina diretamente permaneceu praticamente inalterada nos últimos decênios.

O fato acima observado pode indicar, pelo menos, dois outros fatos que se complementam. É que, se a região de influência direta de Sete Lagoas teve uma tendência de diminuir em direção sul em função do processo de metropolização de Belo Horizonte e em direção noroeste, essa mesma região tem-se mantido estável durante um longo período e, embora possa ter perdido, em termos relativos, em atuação direta, não se pode afirmar que a influência sete-lagoana deixou de ser presente nessas direções. Ela é ainda significativa, porém de uma forma mais difusa e, dependendo da direção, possui diferentes graus de intensidade e de frequência de relacionamentos, fato que fazde Sete Lagoas a principal cidade, a mais bem equipada de toda a região que fica entre os vales dos rios das Velhas e Paraopeba, desde os limites setentrionais da região metropolitana de Belo Horizonte até a represa de Três Marias. Na verdade, em direção oeste o confronto de atuação regional sete-lagoana se dá com a área de atuação de Divinópolis que, assim como Sete Lagoas, parece ter mantido o respectivo comando de sua hinterlândia ao longo das últimas décadas.

A centralidade sete-lagoana tornou-se visível também em inúmeras outras oportunidades, tais como quando se pode observar nas diversas divisões regionais efetuadas por órgãos de planejamento tanto federais como estaduais. Assim é o caso da determinação das microrregiões e mesorregiões urbanas (IBGE,1992), na qual Sete Lagoas, tendo como critério principal a centralidade urbana, surge como centro de uma das mais de trezentas microrregiões identificadas em todo o país. Esse é também o caso da determinação das regiões administrativas, regionalização elaborada pelo governo estadual mineiro (Cetec/IGA, 1997), na qual, Sete Lagoas aparece como o centro de uma das 25 regiões identificadas no Estado.

A cidade de Sete Lagoas ocupa uma posição de destaque na região central mineira no que diz respeito aos alguns aspectos populacionais em 2000. Excetuando-se a metrópole - Belo Horizonte e os municípios metropolitanos, Sete Lagoas, com 184692 habitantes, (na Contagem de População de 2007, foram 217506 habitantes, IBGE, 2007), é que possui a maior população total, além de suplantar Divinópolis, com 183764 habitantes (na mesma Contagem: 209921 habitantes), uma outra cidade média importante da região central. Saliente-se a posição de Sete Lagoas em relação a Belo Horizonte, ou seja, uma vez estabelecido um raio de $100 \mathrm{~km}$ a partir da metrópole, não se encontra nenhuma cidade de porte médio, com uma população tão expressiva e que possa ser igualada a Sete Lagoas.

No que diz respeito à taxa de crescimento para o ano de 2000, Sete Lagoas destaca-se mais uma vez, pois, apresenta um valor bastante expressivo (2.81\% a.a.), maior que o valor apresentado por Belo 
Horizonte (1.13\% a.a.) e por Contagem (2.03\% a.a.), a segunda maior cidade de Minas Gerais. Além do mais, essa taxa, também, é maior que aquelas apresentadas por outras cidades médias como Divinópolis (2.18\% a.a.), Conselheiro Lafaiete (1.62\% a.a.) e Formiga ( $0.19 \%$ a.a.). Essas observações podem ser estendidas à região de influência imediata de Sete Lagoas pois, cidades como Capim Branco, Funilândia, Matozinhos, Papagaios, Paraopeba e Prudente de Morais apresentaram taxas superiores a $2.0 \%$ a.a., fato que as aproxima do comportamento sete-lagoano. Isso pode indicar, também, o reflexo do dinamismo econômico dessa região.

A região central é uma região tipicamente urbana. A grande maioria dos municípios componentes apresenta as maiores taxas de urbanização, acima dos 75\%, Sete lagoas aí incluído, além de: Belo Horizonte e seus municípios metropolitanos, Diamantina, Conselheiro Lafaiete, Corinto, Curvelo, Divinópolis, Formiga, Itabira, Itaúna, Ouro Preto, Pará de Minas e outros.

Uma análise mais detalhada da evolução da população urbana de Sete Lagoas nas últimas décadas demonstra a posição de destaque de Sete Lagoas na região centralmineira. Desse modo, apresenta-se a tabela a seguir:

\begin{tabular}{|c|c|c|c|c|c|c|c|c|c|c|}
\hline \multirow{2}{*}{ POPULAÇÄO } & \multicolumn{5}{|c|}{ ANOS } & \multicolumn{5}{|c|}{ CRESCIMENTO RELATIVO (\%) } \\
\hline & 1960 & 1970 & 1980 & 1991 & 2000 & $60-70$ & $70-80$ & $80-91$ & 91-00 & $60-00$ \\
\hline TOTAL & 41656 & 68585 & 100628 & 143950 & 184692 & 59.8 & 51.1 & 43.1 & 28.3 & 343.4 \\
\hline URBANA & 36482 & 61142 & 94604 & 140060 & 180613 & 67.6 & 54.7 & 48.0 & 29.0 & 395.1 \\
\hline RURAL & 5174 & 5543 & 6024 & 3890 & $407 d$ & 7.1 & 8.7 & -35.4 & 4.8 & -21.2 \\
\hline
\end{tabular}

Nas últimas quatro décadas Sete Lagoas sofreu um expressivo crescimento populacional, notadamente no que respeita à expansão urbana, cujo crescimento relativo no período 1960-2000 foi ainda maior que o próprio crescimento da população total. No que tange à população rural, observa-se uma variação negativa no lapso de tempo considerado, não obstante as variações positivas registradas nas décadas de 1960, 1970 e 1990. Sete Lagoas, assim como a esmagadora maioria dos municípios brasileiros, experimentou o mesmo fenômeno de crescimento da população urbana em detrimento do crescimento populacional rural, o qual se tornou característico do processo da modernização brasileira no período considerado. (NOGUEIRA, 1993). 


\section{A contribuição dos fluxos populacionais - migratórios e pendulares - na análise da centralidade urbana de Sete Lagoas/MG nos períodos de 1975-1980, 1986-1991 e 1995-2000}

Para a análise dos fluxos populacionais - migratórios e pendulares -, de e para Sete Lagoas foram selecionados os primeiros quinze municípios para cada um dos tipos de fluxos, ou seja, emigração, imigração para três períodos distintos: 1975-1980, 1986-1991 e 1995-2000, além dos movimentos pendulares, para o ano de 2000. Tais períodos foram selecionados porque correspondem a importantes momentos de levantamento estatísticos do IBGE, ao longo da segunda metade do século $\mathrm{XX}$. Embora as tabelas elaboradas aqui tragam informações sobre os fluxos entre Sete Lagoas e os cinquentaprincipais municípios, a opção de analisar apenas os quinze primeiros obedeceu ao critério da necessidade de focalizar esse estudo em um universo menor, permitindo uma análise mais pormenorizada daqueles valores mais expressivos.

Os fluxos emigratórios de Sete Lagoas para os três períodos considerados demonstram, em primeiro lugar, o peso, a importância da metrópole mineira. De fato, a saída para Belo Horizonte, destino da maioria dos migrantes sete-lagoanos, é impressionante diante dos números apresentados pelos outros 14 municípios selecionados, nos três períodos. De fato, muito embora tenha havido uma diminuição com o tempo na participação de Belo Horizonte na emigração de Sete Lagoas, esta ainda émuito intensa no período mais recente, ou seja, 39,25\% do emigrantes escolheram a capital estadual com destino no período de 1995-2000; entre 1975-1980 esta participação foi de 48,30\%, diminuindo para o período seguinte para $27,98 \%$, ainda assim, um número expressivo, tal como se pode observar pela análise da Tabela 2.

Uma segunda constatação tem a ver com o predomínio de destinos mineiros nos três períodos. Nesse grupo inserem-se tanto municípios metropolitanos e da própria hinterlândia da cidade, muito próximos da mesma, como aqueles muito distantes. É o caso, por exemplo, de Montes Claros, Uberlândia, Barbacena e João Pinheiro. Por outro lado, salienta-se o peso de São Paulo e Brasília como destinos nos três períodos, ou seja, a importância da maior metrópole e todo o seu imenso poder de atração e da capital federal na emigração de Sete Lagoas. Além da proximidade, parece que, em boa medida, os fluxos emigratórios sete-lagoanos, têm a ver com a procura de lugares com grande centralidade urbana, independente da escala em que for esta exercida - da microrregional à nacional. Essa centralidade, obviamente, relaciona-se à posição ocupada pelo lugar, as cidades em tela, nas redes econômicas, urbanas na essência, ou seja, quanto mais expressiva, maior seria (é) a possibilidade da atração de migrantes (Tabela 2).

Com relação à imigração para Sete Lagoas, a Tabela 3 traz a participação dos principais fluxos segundo os municípios de origem. Belo Horizonte, tal qual na emigração, é a maior, sendo a diferença 
entre esta e os outros 14 municípios muito grande. A metrópole belo-horizontina é a maior fornecedora de migrantes, nos três períodos em tela, sendo sua participação crescente com o passar do tempo: de 23,17\% entre 1975-1980, para 39,40\% entre 1995-2000.

O peso da maior e mais importante metrópole brasileira permanece. De fato, São comparece nos três períodos com participações significativas, sobretudo no período de 1986-1991. A presença do município do Rio de Janeiro só reforça a importância das metrópoles nacionais nos dois fluxos migratórios de Sete Lagoas, principalmente na imigração e no período mais recente, 1995-2000, quando as duas metrópoles possuem expressivas participações (Tabela 3).

É notável a participação, nos três períodos selecionados, de municípios fora da hinterlândia sete-lagoana, sobretudo daqueles localizados em regiões do norte mineiro, enquanto a participação dos municípios da citada hinterlândia é, comparativamente menor. Da Região Metropolitana de Belo Horizonte, há somente um município, Contagem. A compreensão do quadro acima pode estar no fato de ser Sete Lagoas, uma cidade média. Como já é sabido, as cidades médias, enquanto lugares do trabalho e da técnica (SANTOS, 1996 e 2001) constituem-se em pontos de atração de imigrantes justamente porque no atual ambiente da globalização da economia concentram as atividades de produção econômica, como resultado do espraiamento das atividades produtivas das metrópoles. De acordo com Garcia e Nogueira (2008, p. 4 e 5):

A vitalidade econômica (das cidades médias) é atestada por sua grandecapacidade de gerar empregos, absorvendo significativa parcela da força de trabalho, fato aliás, que remete à atração que tais cidades têm sobre os migrantes. A diversificação e a concentração de atividades terciárias (comércio e serviços) indicam a senda da especialização econômica e funcional, o que não impede que tais cidades não possam, também, ter um setor industrial com forte presença na economia local. De acordo com Santos e Silveira (2001, p. 203), “[...] as cidades de porte médio passam a acolher maiores contingentes de classes médias e um número crescente de letrados, indispensáveis a uma produção material, industrial e agrícola, que se intelectualiza". Caracterizam-se tais cidades, no geral, pela excelência dos padrões de qualidade de vida e pela presença de redes de informação, de transporte e de comunicação as mais modernas, garantindo-lhes uma integração e uma interação sincrônica e simultânea com as grandes cidades do país e do mundo. Finalmente, importa salientar, o papel desempenhado pelas cidades médias nas cidades de sua hinterlândia ou área de influência, ou seja, são elas as responsáveis pela difusão do desenvolvimento e de inovações, fato aliás indicativo do grau de importância da cidade média em sua área de atuação imediata.

A análise dos movimentos pendulares, o terceiro fluxo populacional de SeteLagoas, para o ano de 2000, tal como descrito na Tabela 4, traz algumas informações instigantes. Em primeiro lugar, a 
primazia de Belo Horizonte tanto na origem, como, sobretudo, no destino. Certamente, o quantitativo de pessoas que trabalham e/ou estudam em Belo Horizonte, oriundos de Sete Lagoas é muito grande, muito embora, haja alguma expressividade em sentido oposto. Trata-se de uma interação que bem demonstra as articulações entre os dois lugares, pendendo para a metrópole, devido à sua enorme capacidade de polarização dos espaços mais imediatos. Essa articulação, também, pode ser facilmente observada com relação a outros municípios metropolitanos da RMBH.

A articulação com os municípios da própria hinterlândia está representada por 8 lugares na origem e por 6 no destino, em relação a Sete Lagoas. Pode-se afirmar com segurança que tal articulação reforça a polarização da microrregião, garantindo uma parte da centralidade sete-lagoana, uma vez que tal cidade é capaz de oferecer tanto ocupação no mercado de trabalho (atividades secundárias e um terciário bem desenvolvido), como, também, vagas nos ensinos médio profissionalizante e superior (Tabela 2).

Fato que suscita questionamentos é a presença de lugares/municípios muito distantes de Sete Lagoas nesse tipo de fluxo populacional. É o caso de São Paulo, do Rio de Janeiro, as maiores metrópoles nacionais e da cidade de Viçosa na Zona da Mata mineira. Tratar-se-iam de movimentos semanais, quando o(s) indivíduo (s) permanece $(\mathrm{m})$ no destino durante a semana, em dias úteis (de $2^{\mathrm{a}}$ a $\sigma^{a}$ feira), retornando ao seu lugar de origem no fim-de-semana? Esse tipo de pergunta somente será respondido por meio de investigações mais profundas e que não pertencem ao escopo desse trabalho. 
Tabela 2. Sete Lagoas: 1975/2000. Emigrantes municipals segundo municipalidades aelecionadas de destino dos quingueanilos 1975/1980, 1986/1991 e 1995/2000.

\begin{tabular}{|c|c|c|c|c|c|c|c|c|}
\hline \multicolumn{9}{|c|}{ Emlgraço } \\
\hline \multicolumn{3}{|l|}{$1995 / 2000$} & \multicolumn{3}{|l|}{$1936 / 1991$} & \multicolumn{3}{|c|}{$1975 / 1980$} \\
\hline Municiplo & UF & $\mathbf{N}$ & Municlplo & UF & $\bar{N}$ & Municlolo & UF & $\mathbf{N}$ \\
\hline Eelo Hortzonte & MG & 1558 & Eelo Hortzonte & MG & 948 & Eelo Hortzonte & MG & 2419 \\
\hline Curvelo & MO & 242 & Cortspem & $M G$ & $28 B$ & Prudente de Morals & MO & 335 \\
\hline BSo Paulo & BP & 204 & Inhadma & $M G$ & 259 & Erasills & DF & 270 \\
\hline Matozinhos & MO & 199 & Prudente de Morals & $M G$ & 231 & Contspem & MG & 234 \\
\hline Inhauma & MG & 197 & Montes Claros & MG & 201 & Curvelo & MG & 221 \\
\hline Prudente de Morals & MG & 192 & Papapalos & $M G$ & 198 & Pedro Leopoldo & MG & 204 \\
\hline Rlbelrdo das Neves & $\mathrm{MG}$ & 178 & Curvelo & $M G$ & 177 & B.so Paulo & BP & 196 \\
\hline Pedro Leopoldo & MG & 175 & Pedro Leopoldo & $M G$ & 168 & Pirapora & MG & 180 \\
\hline Eraslla & DF & 172 & Eraslila & DF & 167 & Matozinhos & MG & 164 \\
\hline Contapem & MG & 154 & Jequitios & $M G$ & 163 & Feilyiandla & MG & 158 \\
\hline Montes Claros & $\mathrm{MG}$ & 154 & Furlisnda & MG & 155 & Montes Claros & MG & 147 \\
\hline Furlandia & MG & 152 & Paraopeba & MG & 123 & Joso Plnhelo & MG & 133 \\
\hline Joso PInheiro & MG & 138 & Bsidm & MG & 106 & Inhad ma & MG & 132 \\
\hline Uberlsndla & MG & 134 & Earbacena & $M G$ & 104 & Tribs Marlas & MG & 108 \\
\hline Bantana de Plrapama & MQ & 120 & Bso Paulo & BP & 100 & Aracal & MG & 107 \\
\hline Dhinopols & MG & 112 & Dhincpols & $M G$ & 99 & Cordlaburgo & MG & 102 \\
\hline Paraopeba & MQ & 105 & Rlbelrao das Neves & $\mathrm{MG}$ & 97 & Vesoaslano & MG & 99 \\
\hline Jequitba & $\mathrm{MQ}$ & 104 & Matozinhos & MG & 96 & Funland a & $\overline{\mathrm{MG}}$ & 91 \\
\hline Eetim & $\mathrm{MG}$ & 104 & Cordlaburpo & $\mathrm{MG}$ & 85 & Rlo de Janelro & $\mathrm{RJ}$ & 91 \\
\hline Pompeu & MG & 95 & Vitoria & $E B$ & 83 & Rlbelrao das Neves & MG & 85 \\
\hline Cachoelra da Prata & $\mathrm{MO}$ & 95 & Cachoelra da Prats & $M G$ & 81 & Dhinopols & $\mathrm{MG}$ & 80 \\
\hline Banto Andre & BP & 94 & Araqusina & TO & 79 & Paraopeba & MQ & 78 \\
\hline Capim Branco & MG & 89 & Dismantins & $M G$ & 78 & Bantana de Plrapan & MG & 74 \\
\hline lisouna & MG & 84 & Esmeraldas & MG & 77 & Eetim & MG & 69 \\
\hline Lavras & MG & 81 & Bauru & BP & 74 & Formlpa & MG & 69 \\
\hline Dole & MG & 77 & Portelinha & $M G$ & 73 & Golsnis & $\mathrm{GO}$ & 61 \\
\hline Banta Luza & $\mathrm{MQ}$ & 76 & Fortuna de Mnas & $M G$ & 71 & Capim Eranco & MG & 59 \\
\hline Dlsmantins & $\mathrm{MG}$ & 76 & Pindamonhangaba & BP & 70 & Corinto & MG & 58 \\
\hline Pard de Minas & $\mathrm{MG}$ & 74 & Paracatu & $M G$ & 69 & Pompeu & MG & 56 \\
\hline Coronel Fabriclano & MG & 71 & Tribs Marias & $M G$ & 66 & Itauns & MG & 56 \\
\hline Nova LIma & $\mathrm{MQ}$ & 71 & Bantans de Praparns & MG & 64 & Ipatinga & MG & 55 \\
\hline Juk de Fora & $\mathrm{MQ}$ & 71 & Carmo do Paranalog & $\mathrm{MG}$ & 63 & Balvador & BA. & 51 \\
\hline Maratalzes & $E B$ & 67 & Uberisndla & $M G$ & 60 & Caetanopols & $\mathrm{MG}$ & 46 \\
\hline Papagalos & MQ & 65 & Ords & $\overline{C E}$ & 60 & Coronel Fabriclano & $\mathrm{MG}$ & 42 \\
\hline Vsirzea ds Paima & MG & 64 & Eetim & $\mathrm{MG}$ & 57 & Embu-Guaçu & BP & 41 \\
\hline Patos de Minas & MG & 61 & Pompes & $M G$ & 55 & Rio Branco & $A C$ & 40 \\
\hline itsquaguecetubs & BP & 61 & Banta Luz'a & $M G$ & 56 & Jequlths & MG & 38 \\
\hline Aracal & MG & 59 & Arcos & $M G$ & 55 & Dismantins & MG & 38 \\
\hline Jundisl & BP & 57 & Felixidandia & $M G$ & 53 & Guards-Nor & MG & 38 \\
\hline Esid im & $\mathrm{MQ}$ & 55 & Caetandpolls & $M G$ & 50 & Cristallna & $\mathrm{GO}$ & 38 \\
\hline Eameraldas & $\mathrm{MQ}$ & 55 & Valnhos & BP & 49 & Babard & $\mathrm{MG}$ & 37 \\
\hline Fellwisnd a & $\mathrm{MO}$ & 52 & Bantos Dumont & MG & 48 & Uberisndla & $\mathrm{MG}$ & 36 \\
\hline Bso Goncalo do Abae & $\mathrm{MO}$ & 51 & Babard & MG & 48 & Governador Valsdar & $\mathrm{MG}$ & 36 \\
\hline Banto Antonlo do Mor & MG & 51 & Itambscurl & $\mathrm{MG}$ & 47 & Paracatu & MO & 35 \\
\hline Conseiheiro Lafslets & MG & 49 & Gouvels & MG & 45 & Bso Bemardo do Ca & BP & 34 \\
\hline Caetandpols & MG & 45 & Formosa & GO & 45 & B.so Goncalo do Abs & MG & 33 \\
\hline Vinhedo & BP & 45 & larape & $M G$ & 44 & Otvelra & MG & 32 \\
\hline Nova Berrana & MG & 45 & Morada Nova de Mins & MG & 44 & Banta Luzia & MG & 31 \\
\hline Cordlaburgo & MG & 44 & Montanha & $E B$ & 43 & Aragusin & MG & 31 \\
\hline TOTAL & & 6379 & TOTAL & & 5577 & TOTAL & & 6868 \\
\hline TOTAL GERAL & & 8427 & TOTAL GERAL & & 7406 & TOTAL GERAL & & 8330 \\
\hline PERCENTUAL & & 75,7 & PERCENTUAL & & 75,3 & PERCENTUAL & & 82,4 \\
\hline
\end{tabular}


Tabela 3. Sete Lagoas: 1975/2000. Imigrantes municipals aggundo muniklpalldades seleclonadas de origem dos quingOAnlos 1975/1560, 1986r1991 e $1995 / 2000$.

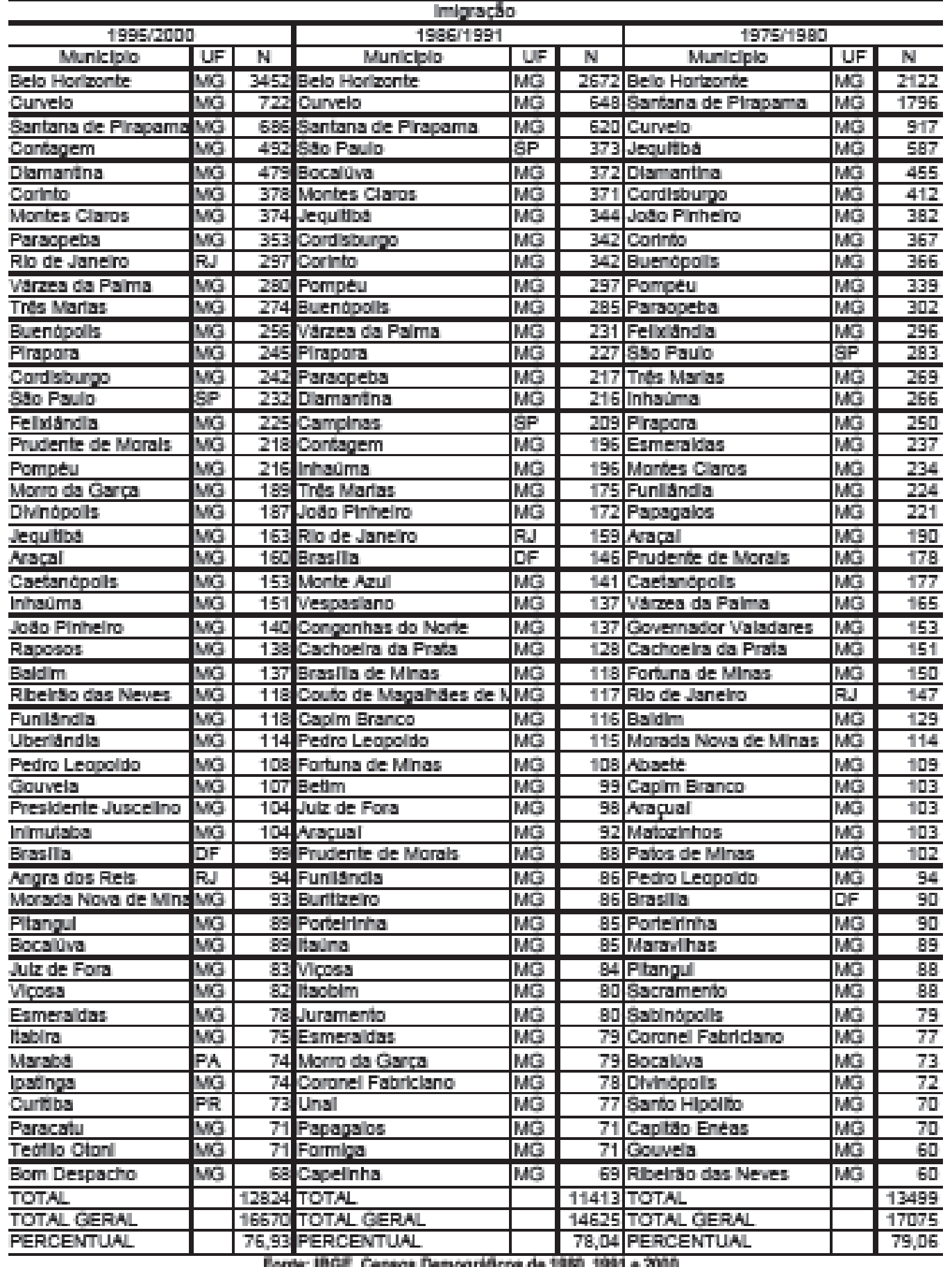


Tabela 4. Sete Lagoss: 2000. Movimentos pendulares aegundo municlpalldades de orlgem $\theta$ destino

\begin{tabular}{|c|c|c|c|c|c|}
\hline \multicolumn{6}{|c|}{ Movimento pendular } \\
\hline \multicolumn{3}{|l|}{ Orlpem } & \multicolumn{3}{|l|}{ Destino } \\
\hline Municiplo & UF & $\mathrm{N}$ & Municiplo & UF & $\mathbf{N}$ \\
\hline Belo Horizonte & MQ & 495 & Belo Horizonte & $M G$ & 2365 \\
\hline Prudente de Morals & MO & 468 & Prudente de Morals & $M G$ & 248 \\
\hline Contapem & $\mathrm{MO}$ & 180 & Bso Paulo & BP & 155 \\
\hline Inhsûms & $\mathrm{MO}$ & 172 & Matozinhos & $\mathrm{MG}$ & 143 \\
\hline Paraopeba & MQ & 143 & Contagem & $M G$ & 140 \\
\hline Cachoeira da Prats & $\mathrm{MG}$ & 129 & Papsagalos & $M G$ & 138 \\
\hline Pedro Leopoldo & MG & 111 & Pedro Leopoldo & $M G$ & 136 \\
\hline Araçal & MG & 106 & Inhsúma & $M G$ & 118 \\
\hline Caetanopolls & MG & 100 & Rlo de Janelro & R.J & 99 \\
\hline Cordlsburgo & MG & 94 & Caetanbpolls & $M G$ & 82 \\
\hline Funllsndla & MG & 87 & Esmeraldas & MG & 72 \\
\hline Curvelo & MG & 82 & Vlcona & $M G$ & 68 \\
\hline Mafozinhos & Mo & 81 & Betim & $M G$ & 65 \\
\hline Betrm & MG & 81 & Funlsndla & MG & 61 \\
\hline Bald Im & MG & 57 & Parsopeba & MO & 56 \\
\hline Esmeraldas & MO & 56 & Cachoelra da Prata & MG & 50 \\
\hline Jequitibs & MG & 52 & Capim Branco & $\mathrm{MG}$ & 47 \\
\hline Bantsna de Prapama & MO & 50 & Curvelo & MG & $\overline{44}$ \\
\hline Gouvela & MG & 45 & Montes Claros & $M G$ & $\overline{43}$ \\
\hline Veapariano & MO & 40 & Cordlsburpo & $\mathrm{MO}$ & 37 \\
\hline Montes Claros & MO & 39 & Aracal & $M G$ & 35 \\
\hline Fortuna de Minas & MO & 39 & Flores de Golas & 60 & 32 \\
\hline Caplm Branco & $\mathrm{MO}$ & 35 & Nora Lima & $\mathrm{MG}$ & 31 \\
\hline Tumalna & MO & 31 & Jequltiba & $M G$ & 30 \\
\hline Bants Luzia & $\mathrm{MO}$ & 29 & Diamantina & $M G$ & 29 \\
\hline Ribeirbo das Neves & $\mathrm{MO}$ & 29 & Uberaba & $M G$ & 29 \\
\hline Tres Marias & MO & 27 & Vespaslano & $M G$ & 29 \\
\hline Plrapora & $\mathrm{MO}$ & 23 & Bantana de Pirapar & $M G$ & 29 \\
\hline Vazante & $\mathrm{MG}$ & 23 & Ouro Preto & $M G$ & 28 \\
\hline Lapos dos Patos & MQ & 22 & Plrapora & $M G$ & 28 \\
\hline Brumadinho & MO & 22 & Corinto & $M G$ & 23 \\
\hline Italna & MO & 22 & Alfenas & $M G$ & 23 \\
\hline Coronel Fabriclano & $\mathrm{MQ}$ & 20 & Pompeu & $\mathrm{MG}$ & 21 \\
\hline Caete & MG & 19 & Buenopols & $M G$ & 19 \\
\hline Presidente Jugcelino & MG & 19 & Murist & $M G$ & 19 \\
\hline Babara & MG & 18 & Dulz de Fors & $M G$ & $\overline{19}$ \\
\hline Pard de MInas & MQ & 18 & Uberiandls & $M G$ & 19 \\
\hline Caratinga & MG & 17 & Nova Berrans & $M G$ & $\overline{16}$ \\
\hline Barso de Cocals & MG & 16 & Florestal & MG & 16 \\
\hline Miguel Pereira & Rd & 16 & Capelinha & $M G$ & 15 \\
\hline Varzea da Paima & MO & 15 & Cachoelio de liapen & EB & 12 \\
\hline Mlnas Novas & MO & 14 & Cabecelra Grande & MG & $\frac{12}{12}$ \\
\hline Guarhses & MG & 14 & tiatalucu & MO & $\sqrt{12}$ \\
\hline S80 Goncalo do Flo P & MO & 14 & Barbacens & MG & $\overline{12}$ \\
\hline Ipainga & MO & $\overline{13}$ & Jalba & MG & $\overline{11}$ \\
\hline $8 s 0$ Joso Evangelleta & MG & 13 & Braslla & DF & $\overline{11}$ \\
\hline Conporhas do Norte & MG & 12 & Rlbeirso das Neves & MG & $\overline{11}$ \\
\hline Lapos asnta & MO & 11 & Barso de Cocals & MG & $\overline{11}$ \\
\hline Barreliros & PE & 11 & Belo Vale & $M G$ & 11 \\
\hline TOTAL & & 3228 & & & 4756 \\
\hline TOTAL GERAL & & 3538 & & & 5731 \\
\hline PERCENTUAL & & 91,2 & & & 82,99 \\
\hline
\end{tabular}


De acordo com Nogueira (2003) a evidência da importância da cidade em suahinterlândia, seu raio de ação, tipo e grau de intensidade das interações estabelecidas com essa hinterlândia deve ser buscada na identificação e análise dos diversos setores econômicos sete-lagoanos.

Destaca-se o papel das atividades agropecuárias na construção da centralidadeurbana ao longo dos séculos XIX e XX, complementadas pelo florescimento das atividades industriais - siderurgia do gusa, do setor de autopeças e da montadora de veículos utilitários leves -, nas últimas décadas do século XX e na primeira do atual, afora todos os itens que conferem, também, importância à cidade: a presença de um hospital regional, de várias unidades de ensino superior e médio profissionalizante, e a modernidade das infra-estruturas viárias, dentre outras .

Os mapas a seguir ilustram em parte esses processos pois demonstram o alcancede relações de Sete Lagoas em Minas Gerais e permite que se observe uma importante dimensão da centralidade urbana da cidade ao espacializar tais articulações, revelando interações socioespaciais e econômicas potenciais com muitas cidades em território nacional (Mapa 1, 2, 3 e 4).

Mapa 1. Sete Lagoas: 1975/2000. Migrantes municipais segundo municipalidades selecionadas deorigem e destino dos quinquênios 1975/1980, 1986/1991 e 1995/2000. Fluxos acima de 1000 pessoas.

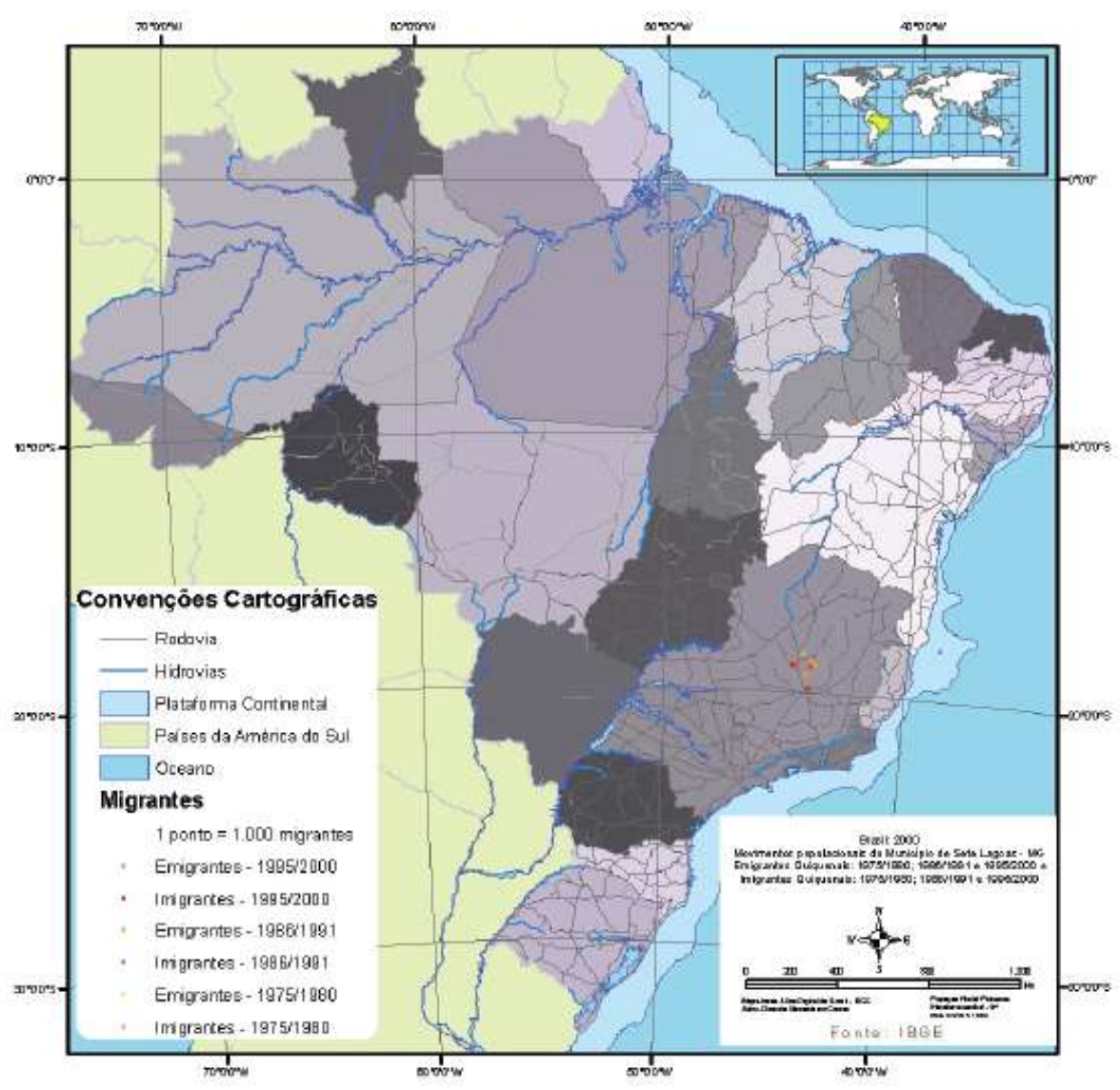

Fonte: IBGE. Censos Demográficos de 1980, 1991 e 2000. 
Mapa 2. Sete Lagoas: 1975/2000. Migrantes municipais segundo municipalidades selecionadas deorigem e destino dos quinquênios 1975/1980, 1986/1991 e 1995/2000. Fluxos de 100 pessoas.

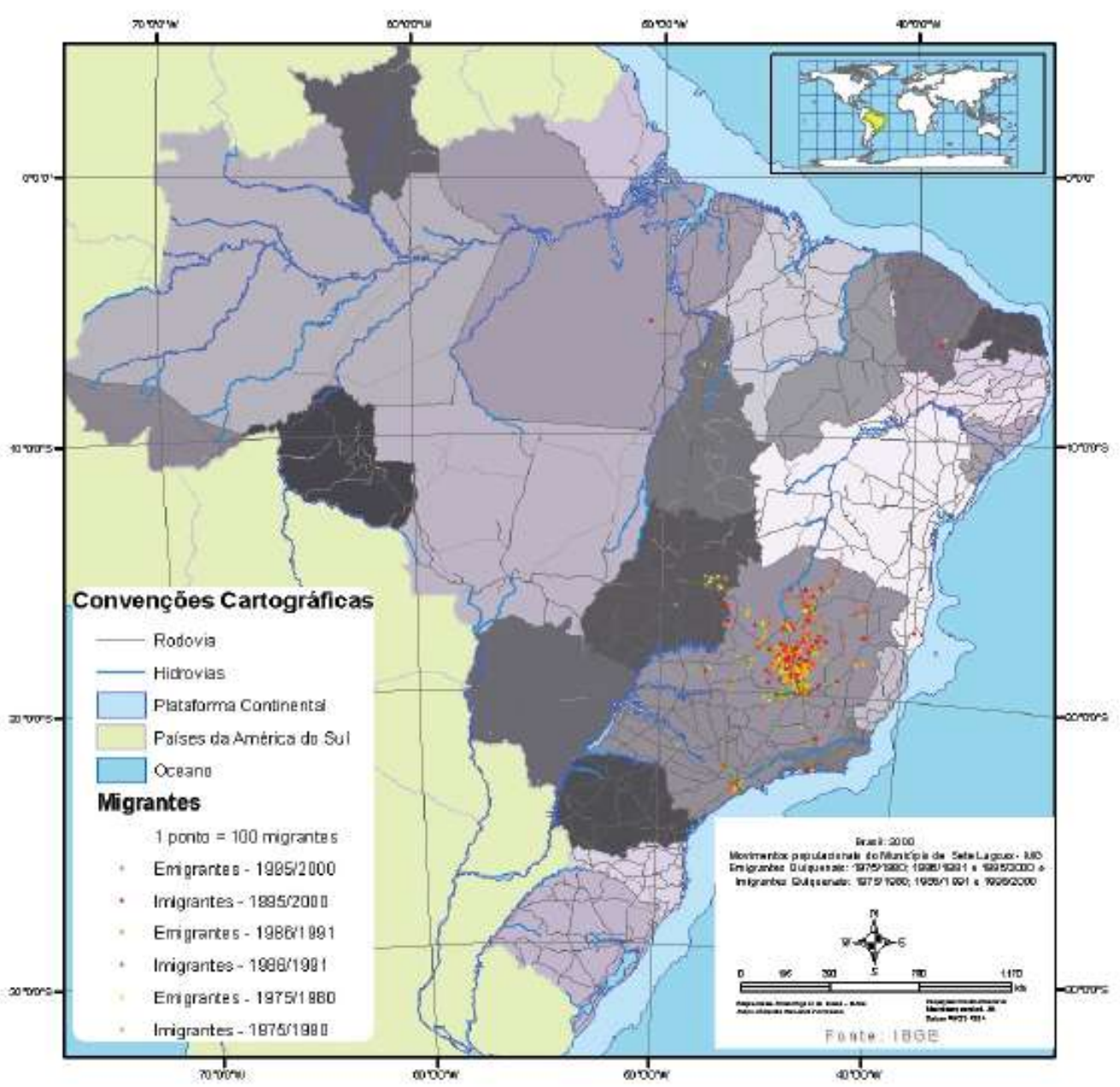

Fonte: IBGE. Censos Demográficos de 1980, 1991 e 2000. 
Mapa 3. Sete Lagoas: 1975/2000. Migrantes municipais segundo municipalidades selecionadas deorigem e destino dos quinquênios 1975/1980, 1986/1991 e 1995/2000. Fluxos de 10 pessoas.

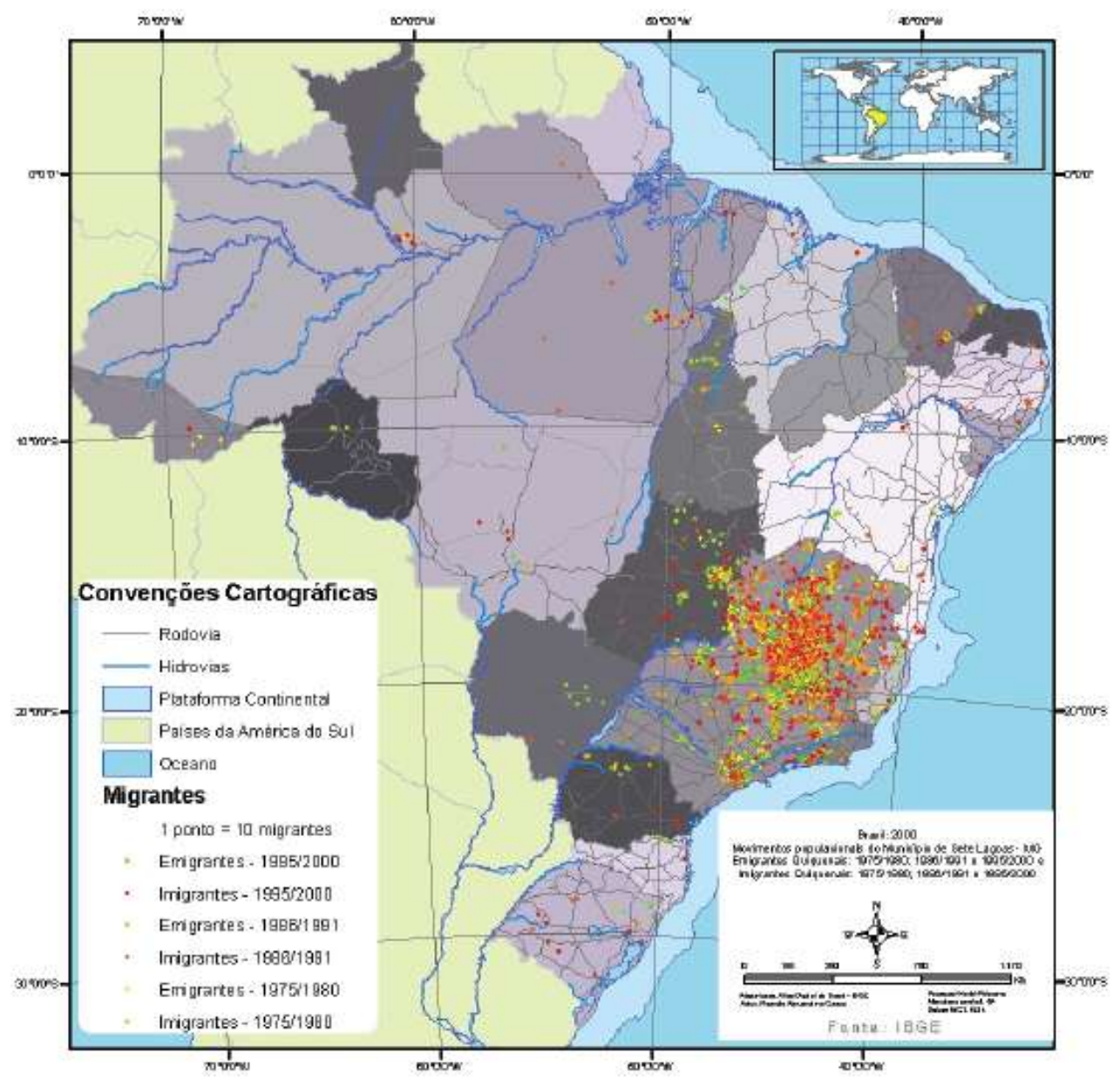

Fonte: IBGE. Censos Demográficos de 1980, 1991 e 2000. 
Mapa 4. Sete Lagoas: 1975/2000. Movimentos pendulares municipais segundo municipalidadesselecionadas de origem e destino em 2000.

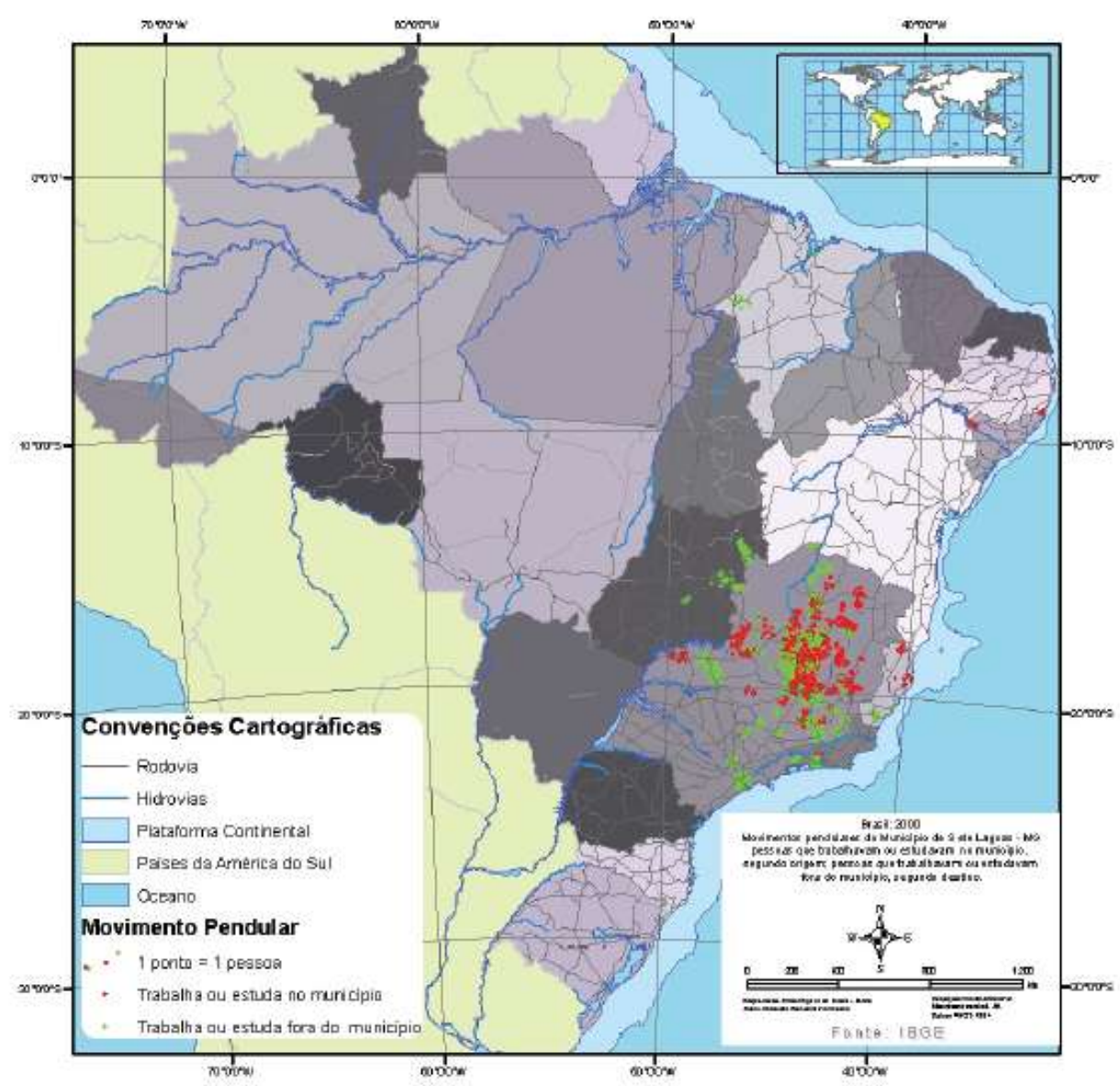

Fonte: IBGE. Censos Demográficos de 1980, 1991 e 2000.

\section{CONSIDERAÇÕES FINAIS}

O destaque que a cidade de Sete Lagoas possui na região central de Minas Geraisconstitui o reflexo de um longo processo de formação e de construção de uma centralidade, a qual por sua vez, reflete-se na atual inserção adquirida pela cidade na rede urbana mineira. Sua posição geográfica, de contato entre duas notáveis regiões mineiras, de porta de entrada do sertão das Gerais, desde sempre foi um fator do mais alto valor, o qual, não passando despercebido pelas pessoas do lugar, constituiu, verdadeiramente, uma base crucial para as argumentações lógicas adotadas por tais pessoas em busca de benefícios para o crescimento e o desenvolvimento da cidade. Sete Lagoas não é apenas um lugar central, distribuidor de bens e serviços para a sua hinterlândia, mas é também um centro urbano possuidor de uma respeitável capacidade de polarização das cidades de sua região, influenciando e 
controlando, por intermédio de sua atividades econômicas, políticas e sociais, o território e a vida de tais cidades. (NOGUEIRA, 2003)

A análise, aqui elaborada, dos fluxos populacionais de e para Sete Lagoasdemonstra que as interações e articulações com as cidades de sua hinterlândia foram confirmadas. Com a cidade/metrópole de Belo Horizonte tais articulações e interações são de extrema relevância; reafirmase a polarização exercida pela metrópole mineirasobre a cidade média. Complementarmente, verificouse que se estabelecem articulações e interações com as três maiores metrópoles nacionais, fato que aliado ao primeiro não invalida a tese da relativa centralidade urbana de Sete Lagoas na rede urbana de Minas Gerais. Afinal, sobre boa parte da mesopotâmia mineira (espaço entre os rios Paraopeba e das Velhas, desde Sete Lagoas até a cidade de Três Marias) essa centralidade/polarização é exercida.

Parece que uma parte das questões levantadas anteriormente foi equacionada,tendo em vista a inegável contribuição da análise dos fluxos populacionais para a inteligibilidade da centralidade urbana sete-lagoana na rede urbana de Minas Gerais. Por outro lado, essa análise não se esgota em si mesma, restando a necessidade da busca de novos estudos que indiquem outras dimensões de análise da problemática, sobretudo, no que se refere ao papel dos movimentos pendulares.

\section{REFERÊNCIAS BIBLIOGRÁFICAS}

ANASTÁSIA, Carla Maria J. A Sedição de 1736: estudo comparativo entre a zonadinâmica da mineração e a zona marginal do sertão agro-pastoril do São Francisco. Belo Horizonte: UFMG, 1983. Dissertação. (Mestrado em Ciência Política).

AZEVEDO, Guiomar Goulart. A região de Sete Lagoas: estudo geográfico. Belo Horizonte: IGC. 1963 a. Tese. (Livre Docência)

BERNARDES, Lysia Maria Cavalcanti. O Rio de Janeiro e sua região. Rio de Janeiro: IBGE. 1964. 164 p.

CRUZ, João José da. Esboço da formação histórico-geográfica de Minas Gerais. Indicadores e Conjuntura, Belo Horizonte: Secretaria de Estado de Planejamento e Coordenação Geral, v. 6, n. 2, p. 186-208, 1984.

FUNDAÇÃO CENTRO TECNOLÓGICO DE MINAS GERIAS (CETEC), INSTITUTO DE GEOCIÊNCIAS APLICADAS (IGA). Estado de Minas Gerais: regiões administrativas. Belo Horizonte: Fundação João Pinheiro, CETEC/IGA, 1997.

FUNDAÇÃO IBGE. Censo Demográfico 2000. Disponível na INTERNET via http://www.ibge.gov.br. Arquivo consultado em 2010.

Contagem da População 2007. Disponível na INTERNET via http://www.ibge.gov.br. Arquivo consultado em 2010. 
.Censo Demográfico de Minas Gerais. Rio de Janeiro: Fundação Instituto Brasileiro de Geografia e Estatística, 1991.

. Divisão do Brasil em regiões funcionais urbanas. Rio de Janeiro: Fundação Instituto Brasileiro de Geografia e Estatística, DEGEO, 1972.

Divisão regional do Brasil em mesorregiões e microrregiões geográficas. Rio de Janeiro: Fundação Instituto Brasileiro de Geografia e Estatística, 1992.

Regiões de influência das cidades. (Coordenação: Roberto Lobato Corrêa). Rio de Janeiro: Fundação Instituto Brasileiro de Geografia e Estatística, Diretoria de Geociências, 1987

GEIGER, Pedro Pedro, CORRÊA, Roberto Lobato. De Vitória a Belo Horizonte pelo vale do Rio Doce. Rio de Janeiro: União Geográfica Internacional. Comissão para os Aspectos Regionais. 1971. 84 p. (Livro-guia da viagem de estudos realizada por ocasião do Colóquio sobre Desigualdades Regionais do Desenvolvimento. Vitória/ES. Abril de 1971)

LIMA JÚNIOR, Augusto de. A capitania de Minas Gerais; origens e formação. 3.ed. Belo Horizonte: Instituto de História, Letras e Arte, 1965.

MATA-MACHADO, Bernardo. O sertão noroeste de Minas Gerais. In: SEMINÁRIO SOBRE A ECONOMIA MINEIRA, 3., 1986, Diamantina. Anais... Belo Horizonte: Cedeplar, FACE/UFMG. 1986. p.93-118.

MINAS GERAIS. Anuário estatístico de Minas Gerais. Belo Horizonte, 1987.

NOGUEIRA, Marly. Interação espacial e metropolização: um estudo de caso via modelo potencial: o Vale do Aço (MG) - 1980/1991. Rio Claro: UNESP/IGCE, 1993. 281 p. Dissertação. (Mestrado em Geografia).

Sete Lagoas: a dinâmica funcional de um lugar na rede urbana de Minas Gerais. Rio de Janeiro: UFRJ/IGEO, 2003. 291 p. Tese (Doutorado em Geografia)

PAULA, TanyaPitanguy de. Abrindo os baús: tradições e valores das Minas e das Gerais. Belo Horizonte: Autêntica, 1999.

SANTOS, Milton. A natureza do espaço: técnica e tempo. Razão e emoção. São Paulo: Hucitec, 1996. $306 \mathrm{p}$.

SANTOS, Milton, SILVEIRA, Maria Laura. O Brasil: território e sociedade no início do século XXI. Rio de Janeiro: Record, 2001. 471 p.

VASCONCELOS, Diogo de. História média de Minas Gerais. 4. Ed. Belo Horizonte: Itatiaia, 1974.

VASCONCELOS, Diogo Pereira Ribeiro de . Breve descrição geográfica, física e política da Capitania de Minas Gerais. Belo Horizonte: Fundação João Pinheiro, 1994.

VASCONCELOS, Agripa. Sinhá Braba - Dona Joaquina do Pompéu. romance do Ciclo Agropecuário nas Gerais. Belo Horizonte: Itatiaia, 1999, 373 p. (Série: Sagas do País das Gerais). 